\title{
Article \\ Optimization of the Rework of Bended OLED Displays by Surface-Energy Control
}

\author{
Young-Gyun Kim ${ }^{1,+}{ }^{+}$, Byung-Min Park ${ }^{2,+}$, Jong-Keun Choi ${ }^{1}{ }^{\oplus}$, Dong-Hoon Jang ${ }^{1}$ and Kwan-Young Han ${ }^{1, *}$ \\ 1 Department of Display Engineering, Dankook University, 119, Dandae-ro, Dongnam-gu, \\ Cheonan-si 31116, Korea; jeffhbk2@naver.com (Y.-G.K.); dk_jkeun@naver.com (J.-K.C.); \\ jjang11991@naver.com (D.-H.J.) \\ 2 Korea Technology Finance Corporation, 33 Munhyeon Geumyung-Ro, Nam-Gu, Busan-si 48400, Korea; \\ bmpark8611@naver.com \\ * Correspondence: kyhan@dankook.ac.kr \\ + These authors contributed equally to this work.
}

check for

updates

Citation: Kim, Y.-G.; Park, B.-M. Choi, J.-K.; Jang, D.-H.; Han, K.-Y. Optimization of the Rework of Bended OLED Displays by Surface-Energy Control. Coatings 2021, 11, 1523. https://doi.org/ $10.3390 /$ coatings 11121523

Received: 6 November 2021 Accepted: 7 December 2021 Published: 10 December 2021

Publisher's Note: MDPI stays neutral with regard to jurisdictional claims in published maps and institutional affiliations.

Copyright: (c) 2021 by the authors. Licensee MDPI, Basel, Switzerland. This article is an open access article distributed under the terms and conditions of the Creative Commons Attribution (CC BY) license (https:/ / creativecommons.org/licenses/by/ $4.0 /)$.

\begin{abstract}
Recent display technology has changed substantially from flat-type displays to bended displays. As a result, the lamination process for bonding the panel substrates and bended window glass has become difficult due to the changes in display shape, and the use of optically clear adhesive (OCA) makes it impossible to rework defective substrates due to residue problems. Therefore, it is necessary to research and develop a substrate-surface treatment that maintains the initial adhesion and is reusable via the complete removal of impurities during delamination in order to enable rework. In this paper, the possibility of maintaining adhesive force and reusing substrates was confirmed through the surface treatment of substrates and OCA using various materials. We found that a surface coating and a cooling treatment of additional substrates completely removed the impurities that remained on the substrates during reworking. These results could contribute to improving lamination-process technology and the productivity of the various forms of next-generation displays that are currently under development.
\end{abstract}

Keywords: organic light emitting diodes(OLED); flexible display; lamination; OCA; rework

\section{Introduction}

Recently, display technology has rapidly changed from conventional flat-type displays to flexible displays [1-5] such as bended, foldable [6-13], curved [14,15], and rollable [16-20] displays. These evolving display types require the appropriate display materials and process technologies. The lamination-process [21-28] technology for bonding panel substrates and bended window glass is one of the most important technologies currently available. In general, the lamination process uses optically clear adhesive (OCA) and optically clear resin (OCR), both of which have excellent optical properties. The reason for this is to minimize the decrease in visibility due to reflection and refraction as light meets the air gap and the glass within a product's display. Previously, OCRs, which are inexpensive and effective in removing microbubbles, were mainly used in lamination. However, using OCR, which has an amorphous liquid form, is difficult when laminating to the edge of bended displays. As a result, due to the development of lamination technology using silicon pads [29-31], OCA, with its excellent workability, has emerged as a promising OCR alternative because it has high adhesion properties and can be shaped into a tape. However, despite advances in the development of lamination technologies and various adhesive materials, the lamination process using OCA is challenged by defects. In addition, the nature of OCA's high adhesive force gives rise to residue generation during the rework process that makes the reuse of defective substrates impossible. If substrates with defects could be recycled, then it follows that the efficiency of the lamination process would be maximized.

In this study, the fluorine [32-35] and chlorosilane organic material [36,37] containing fluorine elements were surface treated in the bended window glass before the existing 
lamination process so that no residue of OCA was left through surface-energy control. However, because fluorinated and chlorosilanated organic matter dramatically lowers the surface energy, it is difficult to obtain high-adhesion properties, which are among the most important conditions of the lamination process. Therefore, by coating OCA with the above materials, or by controlling the coating area on the substrates, we conducted an experiment resulting in high-adhesion properties that were least $90 \%$ as strong as the existing adhesive coatings and that could improve the rework properties while maintaining $0 \%$ residue. In addition, temperature control was implemented in order to maximize the improvement of the rework properties. Therefore, we were able to maximize the rework characteristics by surface treatment with various materials on various substrates and by temperature control. As a result, the substrate-surface treatment investigated in this study could contribute to the improvement of lamination process technology and the productivity of the next generation of displays.

\section{Experimental Methods}

\subsection{Preliminary Experiments}

We conducted experiments to optimize the adhesion and improve the rework characteristics of adhesive coatings by controlling the surface energy of the bended-window-glass substrate. The conditions of the experiments were such that a high adhesion of greater than $90 \%$ compared to the existing adhesives and $0 \%$ residue were maintained. In order to determine the change in adhesion due to the pre-surface treatment, i.e., the plasma surface treatment [38-40], of the substrate, the adhesion was measured for each substrate before and after treatment. The adhesion of the substrate itself was measured using bended window glass (WG), bended black-matrix window-glass 1 (BM1), and bended black-matrix window-glass 2 (BM2) as shown in Figure 1a, and the adhesive used was 3M OCA (OCA film, 3M, Saint Paul, MN, USA). The adhesion was measured using a peel-test machine (Material Testing Machine, Ametek Inc., Berwyn, PA, USA), and was confirmed by performing a $180^{\circ}$ peel test in accordance with the ASTM D3330 standard.

A second experiment was conducted in order to confirm the difference in adhesion before and after $\mathrm{N}_{2}$ plasma surface treatment. The plasma treatment was carried out at a rate of $30 \mathrm{~mm} / \mathrm{s}$ using $300 \mathrm{~L}$ per minute $(\mathrm{lpm})$ of $\mathrm{N}_{2}$ at $1.5 \mathrm{~kW}$ power using $\mathrm{N}_{2}$-plasmatreatment equipment ( $\mathrm{N}_{2}$ plasma equipment, PSM, Seongnam, Korea). The adhesion after plasma treatment was measured in the same way using the same peel-test equipment. Furthermore, in order to analyze the surface-energy effects on the difference in adhesion before and after the plasma treatment, contact-angle and surface-energy measurements were performed using contact-angle equipment (DSA 25, KRÜSS, Hamburg, Germany).

\subsection{Adhesion Difference According to Surface Characteristics of Substrate}

Next, an experiment was conducted in order to investigate the change in adhesion according to the surface characteristics of the substrate. In order to confirm the surfaces of WG, BM1, and BM2, scanning-electron-microscopy (SEM) measurements were performed using a Field Emission-Scanning Electron Microscope (FE-SEM, SIGMA500 Zeiss, Jena, Germany).In addition, energy-dispersive X-ray-spectroscopy (EDS, SIGMA500 Zeiss, Jena, Germany) measurements were performed in order to analyze the materials on the substrate surface, and atomic-force-microscopy (AFM) (Fastscan Bion AFM specifications, Bruker, Billerica, MA, USA) measurements were performed in order to confirm the surface roughness of each substrate. These measurements were used to confirm the mechanism by which the adhesive strength varies depending on the substrate's surface characteristics. 


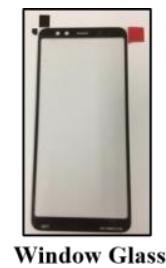

Window Glass

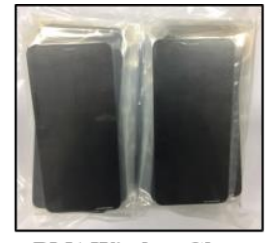

BM1 Window Glass

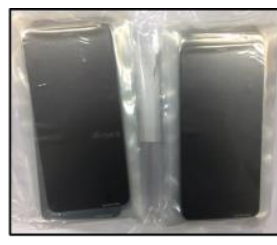

BM2 Window Glass

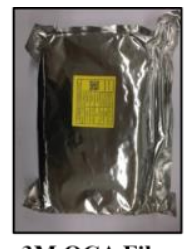

3M OCA Film

(a)

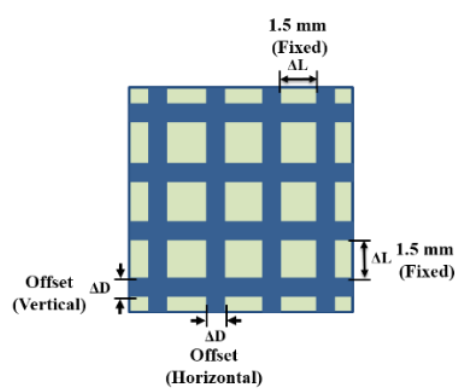

(b)
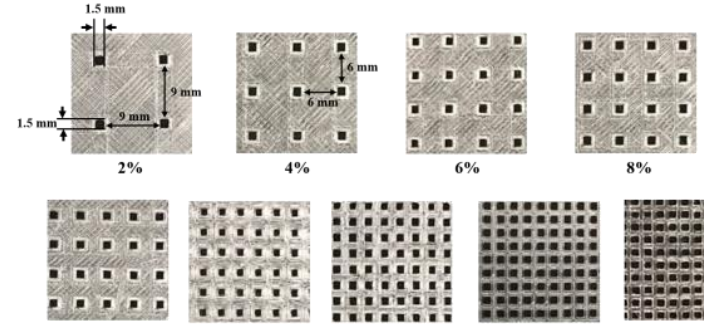

$\because \cdots$

:2.:?

I.......

$20 \%$
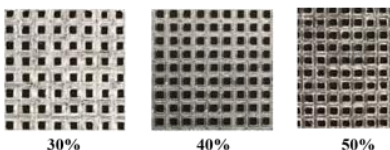

(c)
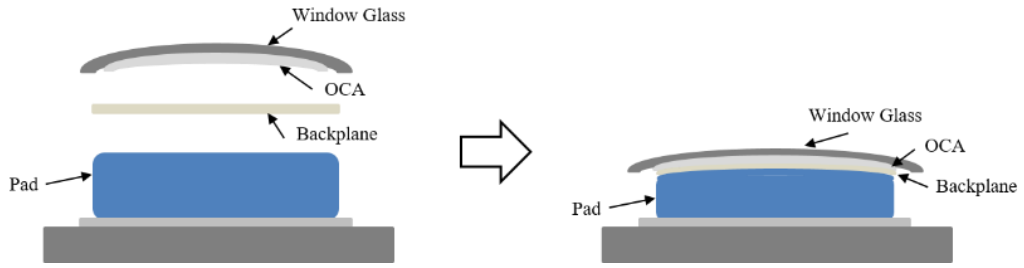

(d)
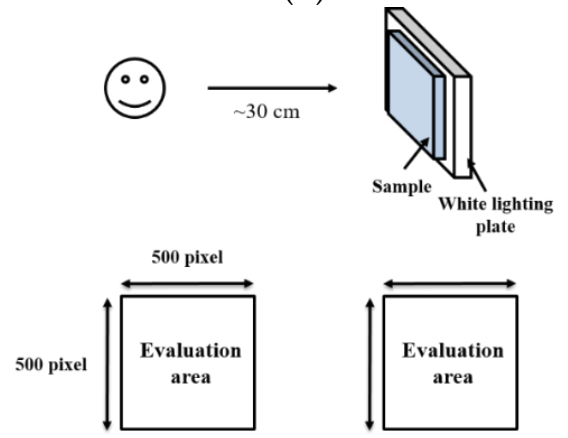

Photographic image

Optical images

(e)
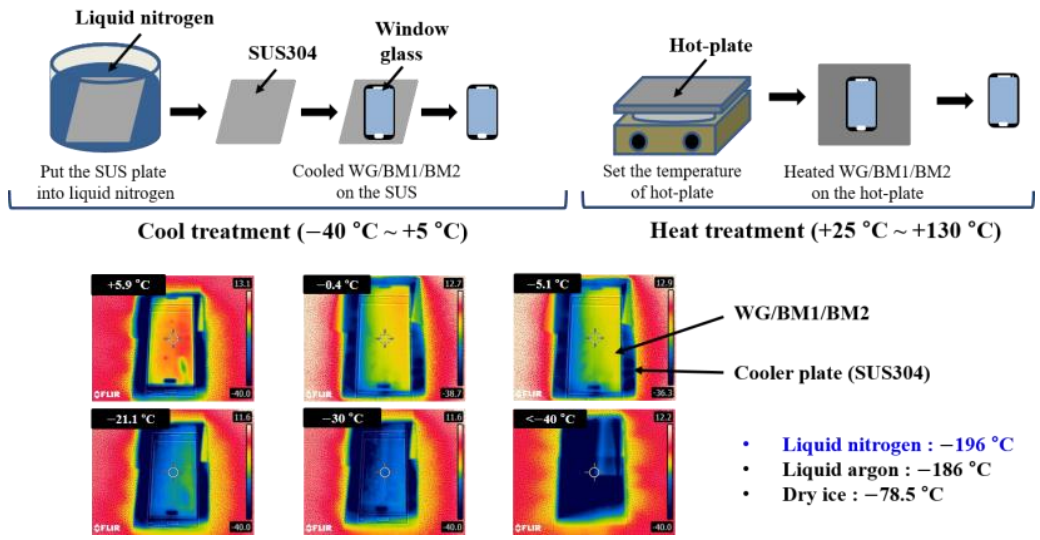

Heat treatment $\left(+25^{\circ} \mathrm{C} \sim+130{ }^{\circ} \mathrm{C}\right)$

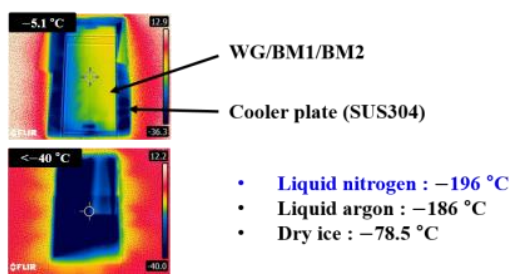

(f)

Figure 1. Materials and measurement methods required for experiments; (a) Bended substrate sample; (b) Pattern mask design; (c) Pattern masks actually made by area; (d) Lamination process of bended window glass and OCA; (e) Visual and image inspection methods after the rework process; (f) Process for temperature treatment. 


\subsection{Surface-Energy Control of Substrates}

When measuring the change in adhesion with respect to the surface energy of the substrate, a surface-energy-control experiment was conducted in which an organic film was formed on the three substrates (WG, BM1, and BM2) that had been previously plasmatreated. Silane-based-material 1 (SIM1), silane-based-material 3 (SIM3), and fluorinebased materials (FLM) were deposited onto a 1.1 T glass slide (HSU-1000412, Marienfeld, Germany) using vacuum-deposition equipment (vacuum-deposition equipment, SIT, Hwaseong, Korea). At this time, deposition was performed for each thickness according to the changes in temperature, pre-heating time, and shutter-open time (coating time). In order to confirm the surface energy of each deposited material and the deposition thickness of the material, the coated substrates were measured using a contact-angle-measuring device. Additionally, because particle aggregation generated by deposition onto surfaces causes problems during the lamination process, an optical microscope (BX51TRF, Olympus Optical Co, LTD, Tokyo, Japan) was used to confirm the presence or absence of particle aggregation through surface measurements of each deposition thickness. The adhesion-measurement experiments were then carried out when the coating material was deposited onto each substrate (WG, BM1, BM2) under the optimized conditions (excellent light transmittance and no particle aggregation).

\subsection{Surface Characteristics According to Coating Area}

The change in the substrate's adhesion, depending on the type of material and the deposition thickness, is very large. Therefore, we conducted an additional experiment in order to finely control the change in the adhesion of the substrate by controlling the coating area of the material. The mask shown in Figure $1 \mathrm{~b}$ was used, and the coating area was controlled through the offset of the mask and manufactured as shown in Figure 1c. Using the manufactured mask, the SIM1, SIM3, and FLM materials were deposited onto $1.1 \mathrm{~T}$ glass slides using vacuum-deposition equipment in the same manner as the experiment conducted above. In order to increase the efficiency of the experiment, only the thickness of each material that had been optimized in the above experiment was tested. In addition, the change in the optical characteristic by the vapor-deposition material is undesirable. Therefore, in order to confirm the change in the optical properties according to the coating area, the transmittance and haze were measured using an ultraviolet-visible light (UV-vis) spectrometer (Optizen 2120UV, MECASYS, Daejeon, Korea) and a haze meter (HM-150, Murakami Color Research Laboratory, Tokyo, Japan), and the adhesion according to the optimized coating area and the deposition thickness for each material on the WG, BM1, and BM2 substrates was measured.

\subsection{Surface-Energy Control of OCA}

SIM material and FLM material were deposited onto OCAs to control the surface energy of the adhesive. Vacuum deposition was performed at a temperature of $80^{\circ} \mathrm{C}$ or higher, so it was not suitable for deposition onto adhesives. Therefore, these materials were deposited using spray-coating equipment (Spray Coating Equipment, UTC, New Brunswick, NJ, USA). Spray coating of the SIM material was carried out with a silane-based solution (SIS) or a fluorine-based solution (FLS). By dispensing at a spray rate of 2.0 to $10.0 \mathrm{cc}$ and at a spray-head speed of $600 \mathrm{~mm} / \mathrm{s}$, the deposition was performed in order to achieve the desired thickness. After deposition, the samples were cured at $60{ }^{\circ} \mathrm{C}$ in a convection oven (OV4-30, Jeiotech, Dajeon, Korea) for $30 \mathrm{~min}$. The light transmittance and haze were measured in order to confirm the change in the optical properties of the coating area. Adhesive-force-measurement experiments were also performed on the coating area for each material.

\subsection{Rework According to Surface Characteristics of Substrates}

Another experiment was conducted in order to check whether organic residues from the OCA tape remained during the window-rework process. As shown in Figure 1d, the 
bending process $[29,30]$ was performed using a pad. After delamination of the samples, an OCA peel test was conducted at room temperature. The substrate surfaces were checked through visual inspection, a camera (Galaxy S 20, Samsung, Giheung, Korea), and optical microscopy, as shown in Figure 1d. The visual inspection of the substrate's condition was performed on a white-lighting plate at a distance of $30 \mathrm{~cm}$, based on a person with visual acuity of 1.5 . A $500 \times 500$ pixel image was obtained using a camera attached to the optical microscope at $10 \times$ magnification under a light intensity of 300 to 400 lux.

The complete removal of organic residues from the OCA tape while maintaining high adhesion at room temperature is limited in some samples. Therefore, the temperature control was performed as shown in Figure 1f, and experiments were conducted in order to confirm the rework characteristics of the temperature-controlled samples. In order to observe the characteristics of the rework process at a low temperature, an SUS 304 sample plate was cooled in liquid nitrogen for $5 \mathrm{~min}$ to a temperature of $-40^{\circ} \mathrm{C}$. This allowed for temperature control from -40 to $0{ }^{\circ} \mathrm{C}$. Above room temperature, the SUS 304 sample-plate temperature was controlled using a hot plate. The WG, BM1, and BM2 substrates that were laminated using OCA were placed on the temperature-controlled SUS substrate, and a peel test was performed at the desired temperature. This experiment confirmed a change in the adhesive strength and rework characteristics with respect to temperature.

\section{Results \& Discussion}

\subsection{Adhesion Change through Surface Properties and Surface-Energy Control}

The goal of this study was to optimize the adhesion and improve the rework characteristics (while maintaining a high adhesion of more than $90 \%$ compared to the conventional adhesion methods, and $0 \%$ residue) This was achieved by controlling the surface energy of the bended-window-glass substrates. Preliminary experiments were conducted using an $\mathrm{N}_{2}$ plasma surface treatment on each substrate in order to observe a change in the surface energy. The measurement results of the adhesion to each substrate before and after $\mathrm{N}_{2}$ plasma surface treatment are as follows. Prior to treatment, the adhesion was $8217.1 \mathrm{gf}$ for WG, 9915.3 gf for BM1, and 9529.7 gf for BM2. After surface treatment, the adhesion was measured as 8608.2 $\mathrm{gf}$ for WG, 10,299 $\mathrm{gf}$ for BM1, and 10,044 $\mathrm{gf}$ for BM2, indicating an increase in the adhesive strength of $\sim 400 \mathrm{gf}$ or more. The increased adhesion strengths of the WG, BM1, and BM2 substrates are all due to the increase in surface energy following $\mathrm{N}_{2}$ plasma surface treatment. Therefore, before further experimentation, the adhesion strength was increased through $\mathrm{N}_{2}$ plasma surface treatment on each substrate.

The variance in the adhesion strength with respect to the surface characteristics of each of the $\mathrm{N}_{2}$-plasma-treated substrates (WG, BM1, BM2) was confirmed, and the results are shown in Figure 2a. The adhesion strengths for WG, BM1, and BM2 were measured to be $8608.2,10,299$, and 10,044 gf, respectively. The surface profiles of each substrate after plasma treatment were evaluated. Each substrate surface was imaged using SEM. The results are shown in Figure 2b, and it is clear that BM1 and BM2 have rougher surface shapes and bumps compared to WG. Figure $2 b$ also shows the EDS results for each substrate. The surfaces and bumps on BM1 and BM2 are shown to be composed of carbon and inorganic compounds. The surfaces of WG, BM1, and BM2 were analyzed with $\alpha$-step and AFM equipment in order to observe macro-scale and micro-scale features, respectively. The surface profiles for the substrates are shown in Figure 2c. The inorganic compound bumps contributed to the increased surface roughness in BM1 and BM2 as compared with WG, as shown in Figure 2c. The AFM measurements quantified this roughness. As shown in Figure 2d, the surface roughness RMS values are $1.781 \mathrm{~nm}$ for WG, $37.369 \mathrm{~nm}$ for BM1, and $55.835 \mathrm{~nm}$ for BM2. The results show that BM1 and BM2 are quantifiably rougher than the WG substrate. The relationship between the change in the adhesion and substrate-surface roughness is shown in Figure 2e. It can be deduced that greater roughness translates to more contact area due to bumps, which in turn increases adhesion. Figure $2 \mathrm{f}$ shows that the BM1 and BM2 substrates have a larger surface contact area than the WG substrate due to 
their surface roughness. In addition, it was found that the adhesion from the BM1 and BM2 samples was greater due to strong molecule-molecule interactions from the surface bumps.

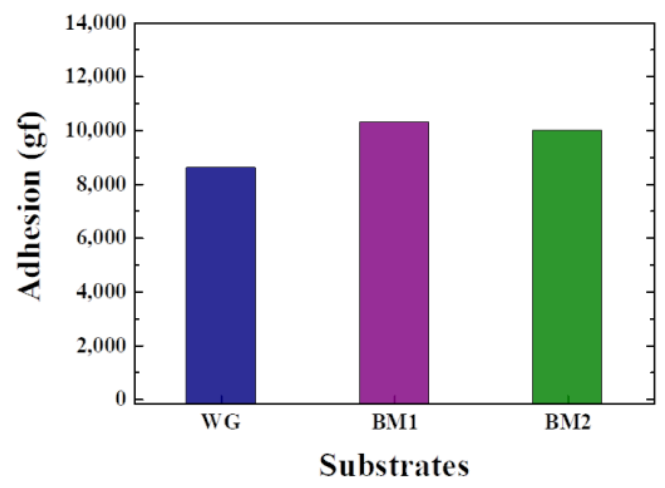

(a)

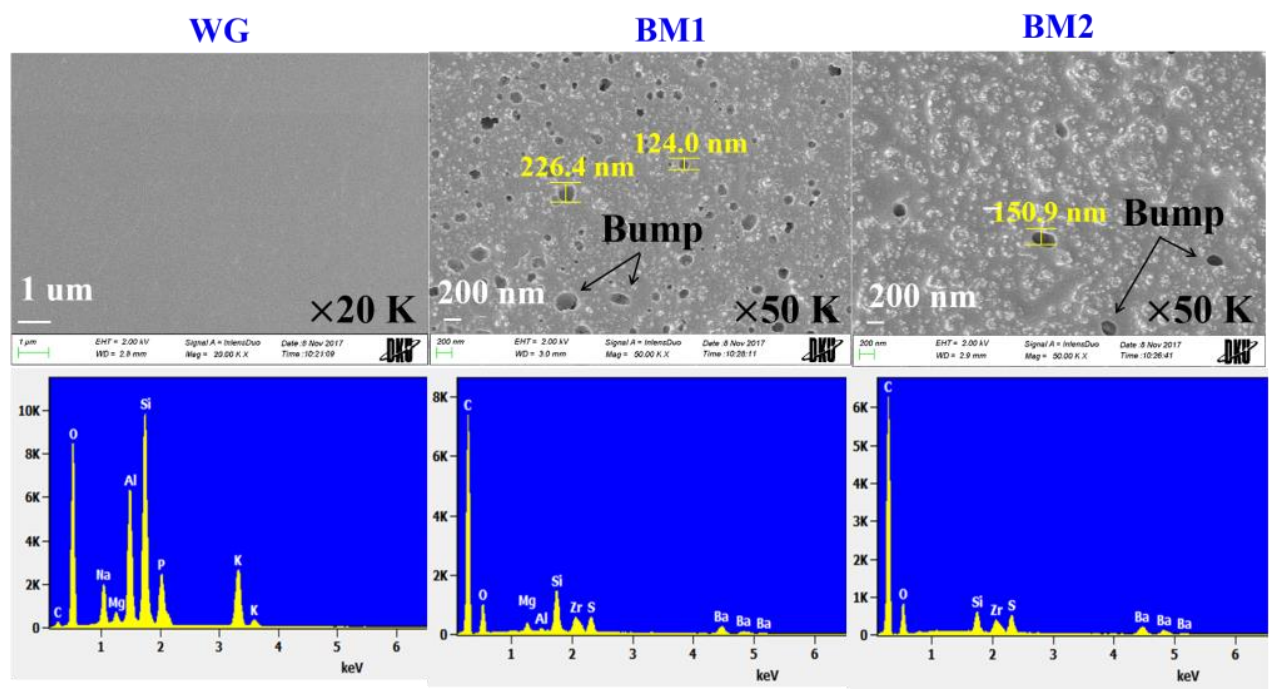

(b)

Surface of WG

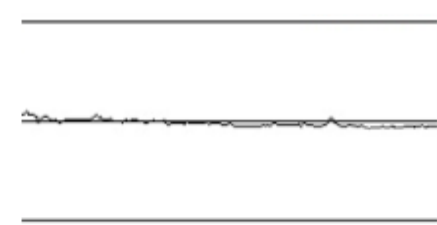

(c)

Figure 2. Cont. 


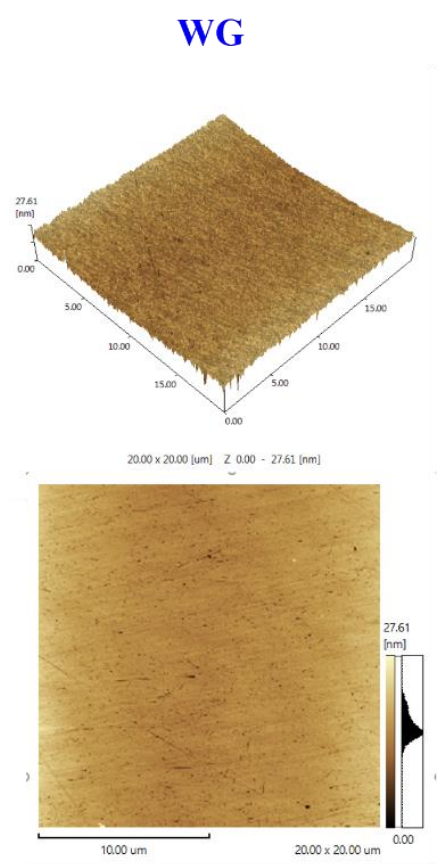

$\mathrm{Ra}: 1.781 \mathrm{~nm}$

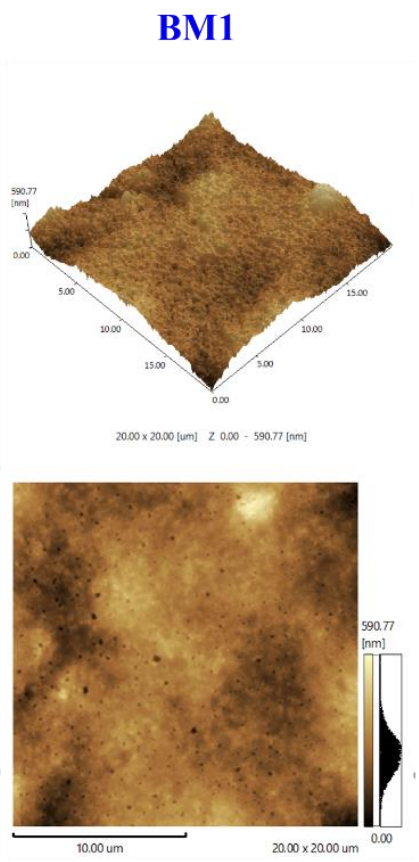

Ra : 37.369 nm
BM2
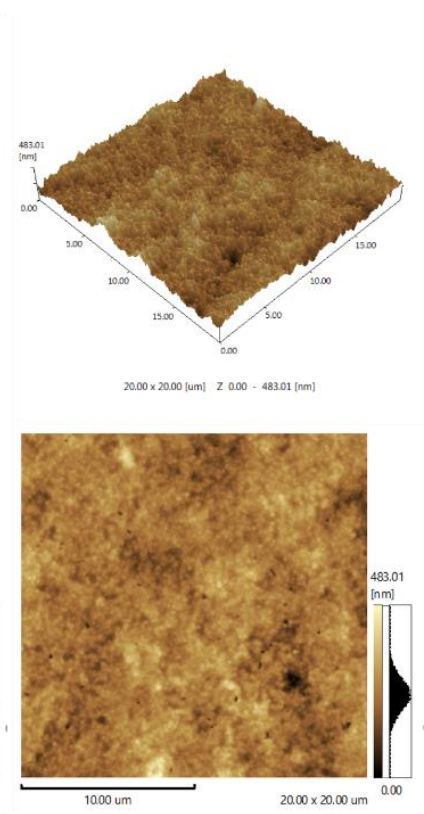

$\mathrm{Ra}: \mathbf{5 5 . 8 3 5} \mathbf{n m}$

(d)

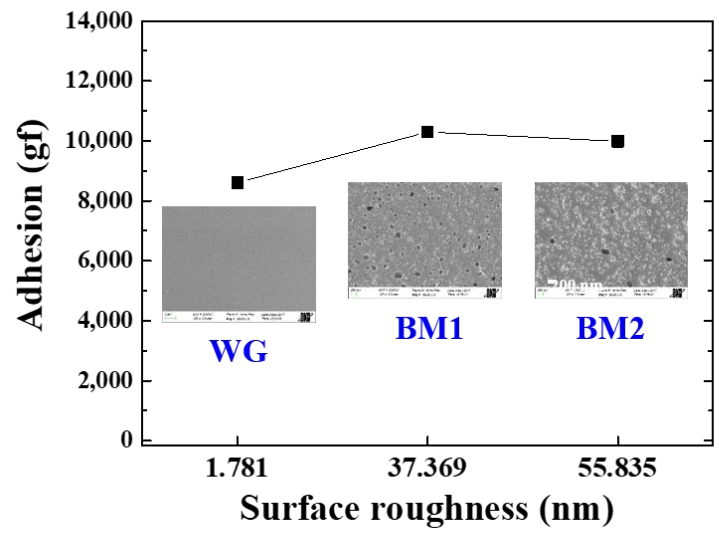

(e)

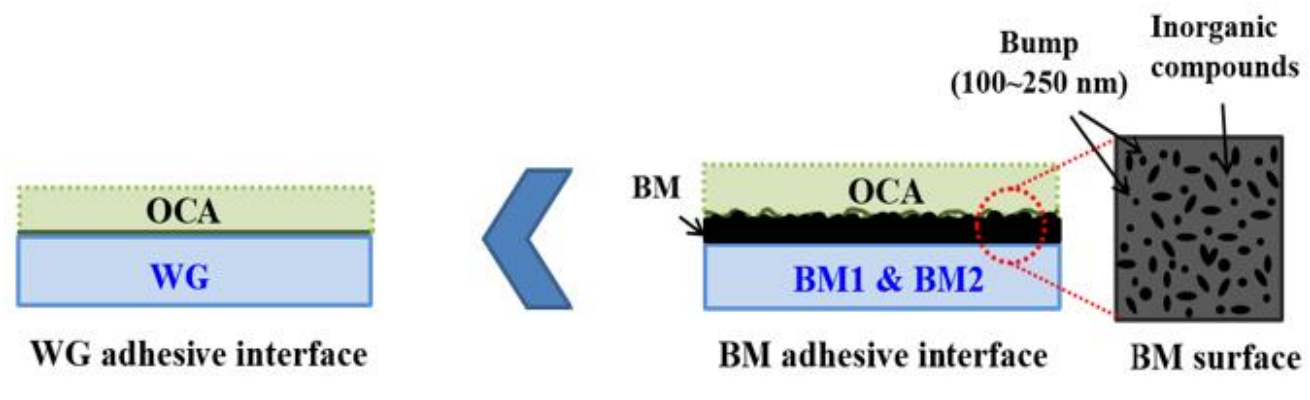

(f)

Figure 2. Adhesion change through surface properties; (a) Adhesion by type of substrate; (b) SEM image measurement to confirm the surface of each substrate and EDS verification to confirm the components of each substrate; (c) Roughness difference between WG and BM1\&BM2 substrates; (d) AFM measurement to confirm the surface of each substrate; (e) Adhesion according to surface roughness of each substrate; (f) A schematic diagram of the difference between the adhesive interfaces of WG substrate of WG and BM1\&BM2 substrates. 
As described above, various materials were used to apply the coatings to substrates in order to yield a different surface roughness and surface energy. In order to improve the efficiency of the rework, as shown in Figure 3a, lower surface energy and lower adhesion characteristics were prioritized. For the surface coating, materials containing fluorine and chlorosilane organics (FLM, SIM) were best because they lowered the surface energy, as shown in Figure $3 b$. These materials were deposited with varying thickness, and the resulting surface-energy values with respect to the FLM- and SIM-deposit thickness are shown in Figure 3c. With the FLM materials, the surface energy was sharply lowered to 19.3 $\mathrm{mN} / \mathrm{m}$ at $5 \mathrm{~nm}$ thickness; above $10 \mathrm{~nm}$ thickness, the surface energy remained constant at about $14 \mathrm{mN} / \mathrm{m}$. On the other hand, the surface energy of the SIM1 material was lowered to $39.24 \mathrm{mN} / \mathrm{m}$ at $5 \mathrm{~nm}$, and it was found that the surface energy remained constant at about $40 \mathrm{mN} / \mathrm{m}$ over a thickness of $10 \mathrm{~nm}$. These results demonstrate that it is possible to lower the surface energy by depositing FLM and SIM onto the substrates. The relationship between deposition thickness and particle agglomeration was measured through optical microscopy, as shown in Figure 3d. The deposition thickness was approximated using pre-heating and coating time according to the deposition-equipment specifications. The actual coating thickness was confirmed by spectroscopic ellipsometry (Elli-SE-U, Ellipso Technology, Suwon, Korea). No particle aggregation was observed for FLM and SIM1 at thicknesses of $10 \mathrm{~nm}$ or less, and SIM3 did not generate particle aggregation at a thickness of $5 \mathrm{~nm}$. Together, these results indicate which combinations of materials and conditions yield usable display substrates. The appropriate deposition thicknesses for FLM, SIM1, and SIM3 were found to be 5, 10, and $5 \mathrm{~nm}$, respectively. After deducing the appropriate deposition thicknesses for each coating materials, each material was deposited onto WG, BM1, and BM2 substrates. The resulting adhesion was measured and is shown in Figure 3e. A requirement of this process is that adhesion is maintained prior to reworking. Therefore, the adhesion force of a surface-coated substrate should be at least $90 \%$ of the adhesive force of each original substrate (WG: $8608.2 \mathrm{gf}, \mathrm{BM} 1:$ 10,299 gf, BM2: 10,044 gf) after conventional plasma treatment (WG: 7747.38 gf, BM1: 9269.1 gf, BM2: 9039.6 gf). The adhesion maintenance condition of $90 \%$ was satisfied only when SIM1 was applied with a thickness of $5 \mathrm{~nm}$ to the BM1 and BM2 substrates. This demonstrates that it is difficult to maintain adhesion by depositing FLM and SIM materials, which reduce surface energy, onto the entire substrate surface. This is because, as shown in Figure 3f, the adhesive force decreases rapidly due to the characteristics of the surface energy that is rapidly lowered from the deposition of the FLM and SIM materials. Furthermore, the differences in the substrates' adhesion are also attributed to different surface characteristics, e.g., surface roughness, the number of bumps, and the difference in the molecule-molecule interactions from the bumps.

In order to maintain $\geq 90 \%$ adhesion (compared to existing substrates) while also maintaining the aforementioned surface characteristics, the deposition was carried out using a pattern mask with an adjusted coating area using the optimal thickness for each material tested above. This is because the adhesive force can be controlled by controlling the contact area through SIM and FLM materials that lower the surface energy as shown in Figure 3f. As the light-transmittance and haze characteristics should not be lowered by the deposition material, the light transmittance was confirmed by depositing the optimum thickness for each material. The light-transmittance measurements show that $4 \%, 10 \%$, $30 \%, 50 \%$, and $100 \%$ of the FLM, SIM 1 , and SIM 3 coated substrate samples had $\geq 90 \%$ light transmittance, as shown in Table 1. In addition, as shown in Table 1, measuring the haze by the area of each material that was deposited with a thickness of 5 or $10 \mathrm{~nm}$ revealed that $4 \%, 10 \%, 30 \%, 50 \%$, and $100 \%$ of the samples had optimal haze values below 0.3 . 


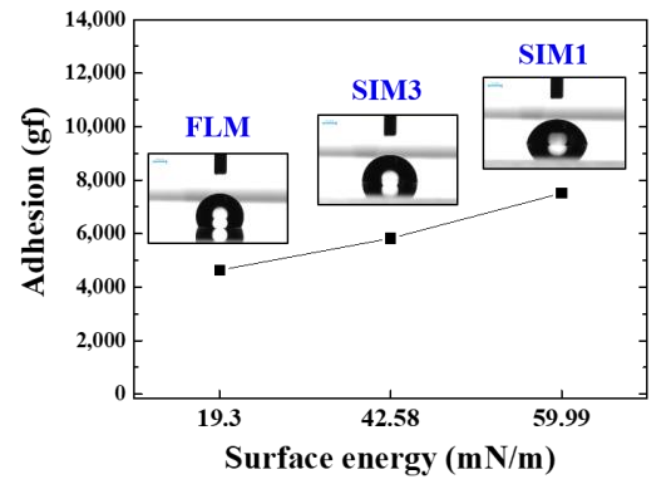

(a)

Fluorine-based materials (FLM)

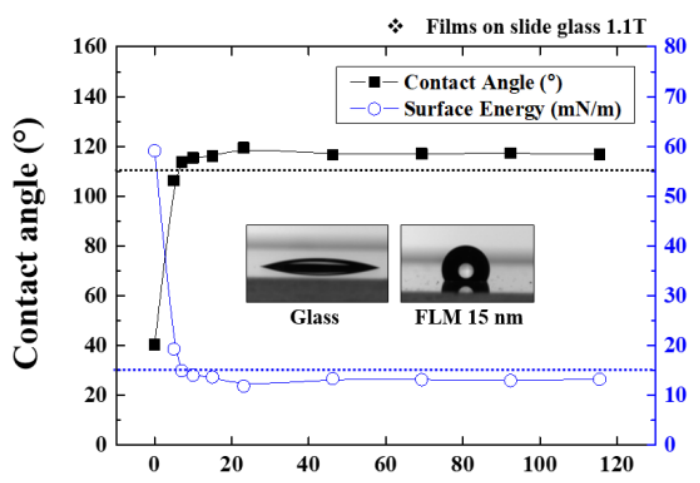

Thickness of fluorine-based film (nm)

Fluorine-based materials (FLM)
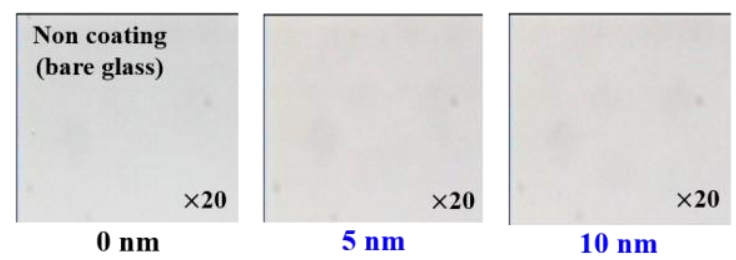

Particle aggregation

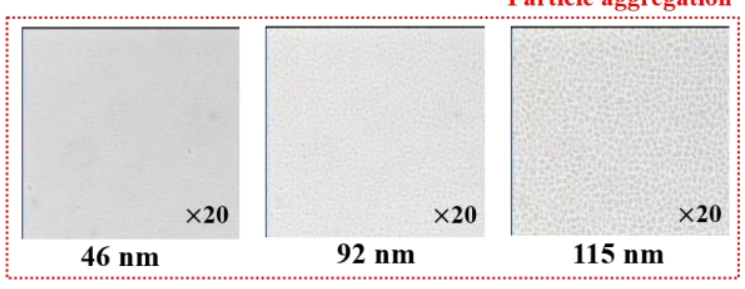

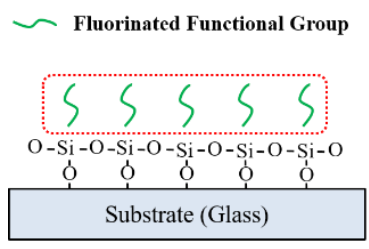

- R1, R2 : Organic Carbon Functional Group

(b)

Silane-based materials 1 (SIM1)

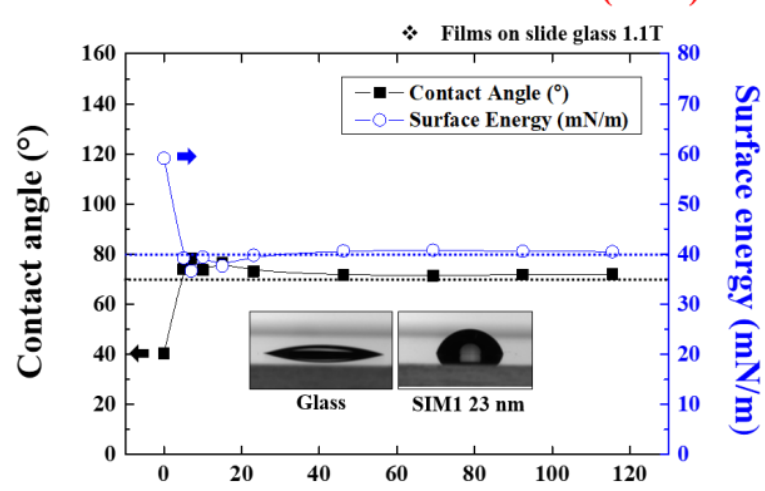

Thickness of silane-based film (nm)

(c)

Silane-based materials 1 (SIM1)
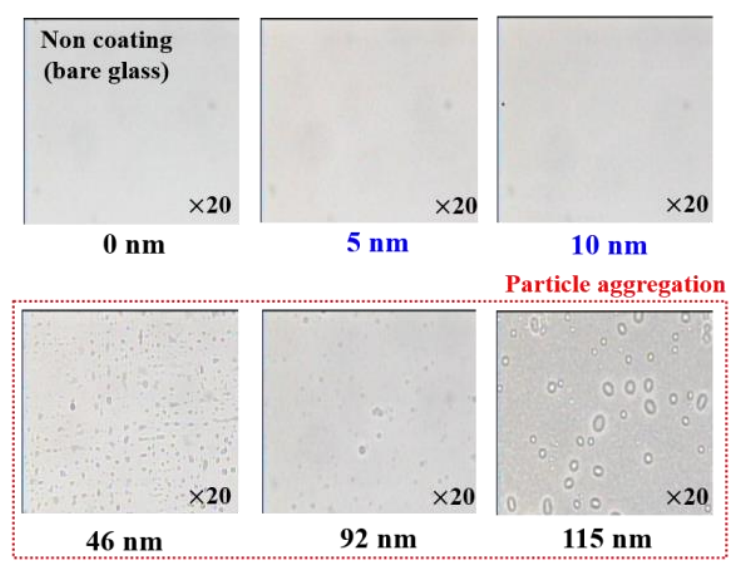

Silane-based materials 1 (SIM3)
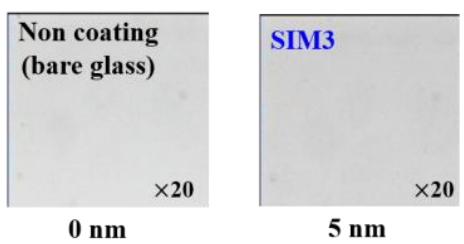

(d)

Figure 3. Cont. 
Fluorine-based materials (FLM)

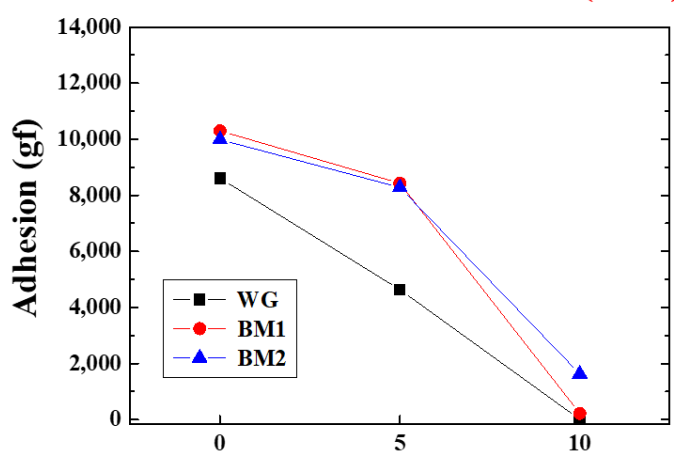

Thickness of FLM film (nm)
Silane-based materials (SIM1)

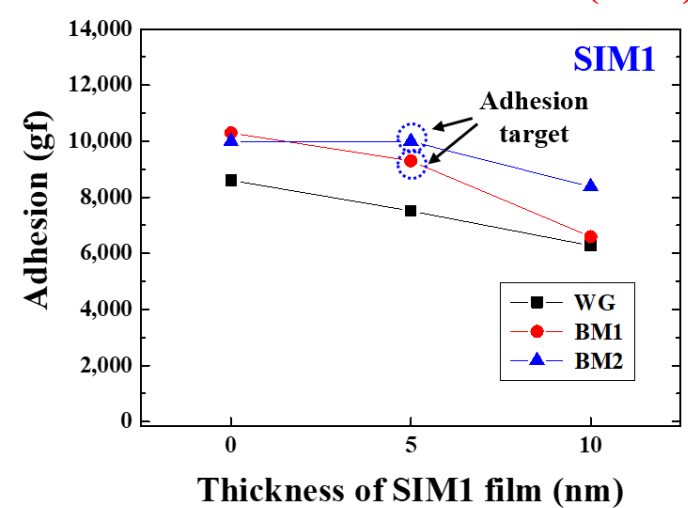

Silane-based materials (SIM3)

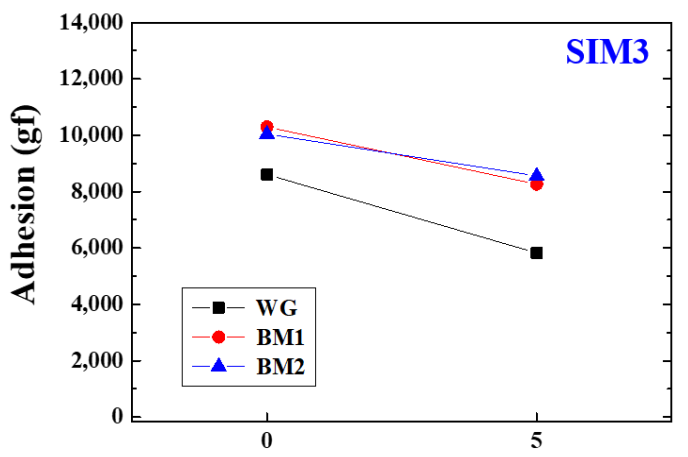

Thickness of SIM4 film (nm)

(e)
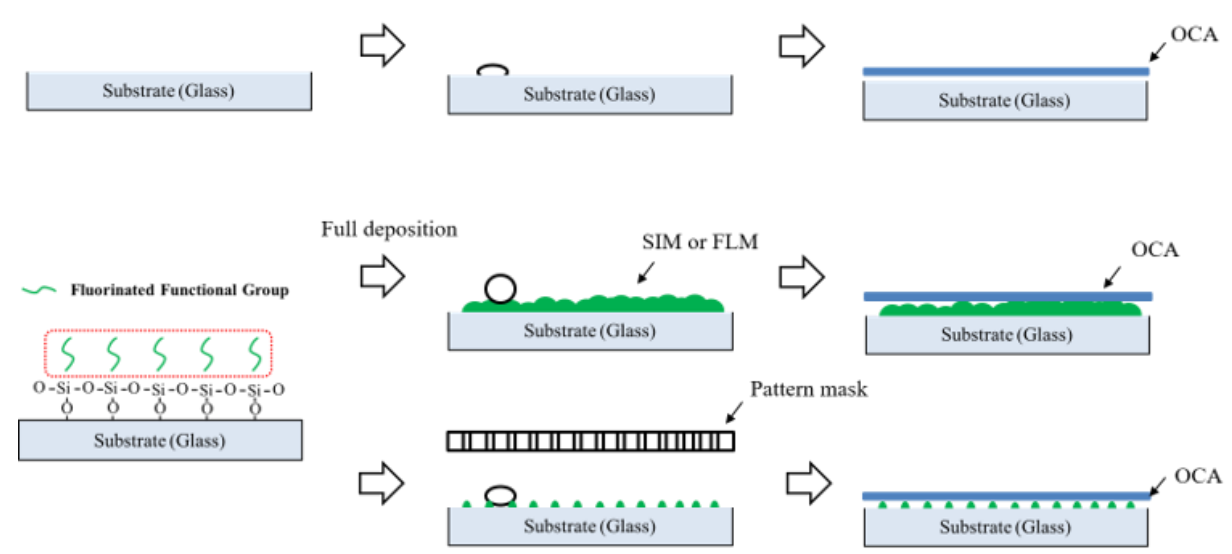

(f)

Figure 3. Adhesion change through surface-energy control on substrates; (a) Adhesion according to surface energy of each substrate; (b) A schematic diagram of a material containing fluorine and chlorosilane organic matter; (c) Contact angle and surface energy by FLM and SLM deposition thickness; (d) Confirmation of particle aggregation according to FLM- and SLM-deposition thickness through optical microscopy; (e) Confirm adhesion changes according to deposition thickness of FLM, SIM1, and SIM3; (f) The mechanism for adhesion change according to SIM and FLM. 
Table 1. Transmittance and Haze according to deposition area and type.

\begin{tabular}{|c|c|c|c|c|c|c|c|}
\hline \multirow{2}{*}{ NO. } & \multirow{2}{*}{ Samples } & \multicolumn{6}{|c|}{ Ratio of Coated Area (\%) } \\
\hline & & $\mathbf{0}$ & 4 & 10 & 30 & 50 & 100 \\
\hline \multicolumn{8}{|c|}{ The light transmittance target: $\geq 90 \%$} \\
\hline 1 & FLM $5 \mathrm{~nm}$ & $92.18(\%)$ & 91.75 & 91.65 & 91.47 & 91.34 & 92.53 \\
\hline 2 & FLM 10 nm & $91.53(\%)$ & 92 & 92.34 & 91.86 & 91.73 & 92.88 \\
\hline 3 & SIM $15 \mathrm{~nm}$ & $92.18(\%)$ & 92.41 & 92.06 & 91.74 & 91.55 & 92.81 \\
\hline 4 & SIM $110 \mathrm{~nm}$ & $91.56(\%)$ & 91.93 & 91.53 & 91.37 & 90.92 & 91.65 \\
\hline 3 & SIM $35 \mathrm{~nm}$ & $91.53(\%)$ & 93.09 & 93.42 & 93.55 & 94 & 92.84 \\
\hline \multicolumn{8}{|c|}{ Haze $\leq 0.3$} \\
\hline 1 & FLM $5 \mathrm{~nm}$ & 0.08 & 0.11 & 0.1 & 0.09 & 0.1 & 0.19 \\
\hline 2 & FLM $10 \mathrm{~nm}$ & 0.09 & 0.12 & 0.09 & 0.07 & 0.09 & 0.17 \\
\hline 3 & SIM $15 \mathrm{~nm}$ & 0.08 & 0.11 & 0.08 & 0.06 & 0.08 & 0.13 \\
\hline 4 & SIM $110 \mathrm{~nm}$ & 0.07 & 0.11 & 0.09 & 0.07 & 0.11 & 0.14 \\
\hline 5 & SIM $35 \mathrm{~nm}$ & 0.08 & 0.11 & 0.09 & 0.09 & 0.12 & 0.15 \\
\hline
\end{tabular}

FLM and SIM deposition are acceptable for use on display substrates when adjusting the surface area that is deposited. The change in adhesion with respect to the deposition area for each material on the WG, BM1, and BM2 substrates is shown in Table 2. On the WG substrate, FLM ( 5 and $10 \mathrm{~nm}$ ) maintained adhesion when the deposition area was within $10 \%$, SIM1 and SIM3 (5 nm) maintained adhesion when the deposition area was within $50 \%$, and SIM1 $(10 \mathrm{~nm})$ maintained adhesion when the deposition area was within $4 \%$. The conditions for maintaining adhesion are shown in Table 2. For BM1, FLM ( 5 and $10 \mathrm{~nm}$ ) was within $50 \%$ of the deposition area, SIM1 $(5 \mathrm{~nm})$ was within $50 \%$ of the deposition area, and SIM1 $(10 \mathrm{~nm})$ and SIM3 $(5 \mathrm{~nm})$ were both within $30 \%$ of the deposition area. As shown in Table 2, for BM2, FLM ( 5 and $10 \mathrm{~nm}$ ) was within $50 \%$ of the deposition area, and SIM1 $(5$ and $10 \mathrm{~nm}$ ) and SIM3 $(5 \mathrm{~nm})$ were both within $50 \%$ of the deposition area. As the deposition area decreased, the deposition of FLM and SIM materials (which reduce surface energy) also decreased. As a result, the optimized surface-area treatment that can increase the rework efficiency while maintaining adhesion was confirmed.

Table 2. Adhesion according to deposition area and type.

\begin{tabular}{|c|c|c|c|c|c|c|c|}
\hline \multirow{2}{*}{ NO. } & \multirow{2}{*}{ Samples } & \multicolumn{6}{|c|}{ Ratio of Coated Area (\%) } \\
\hline & & 0 & 4 & 10 & 30 & 50 & 100 \\
\hline \multicolumn{8}{|c|}{ WG Adhesion target: $7747.3 \pm 200 \mathrm{gf} /$ in } \\
\hline 1 & FLM 5 nm & \multirow{5}{*}{$\begin{array}{c}8,608.2 \\
\text { (gf) }\end{array}$} & 7947.3 & 7757.2 & 6849.4 & 6710.9 & 4638.6 \\
\hline 2 & FLM $10 \mathrm{~nm}$ & & 8224.7 & 7986.1 & 5705.0 & 1142.2 & 11.101 \\
\hline 3 & SIM1 5 nm & & 8239.95 & 8041.7 & 7709.8 & 7792.8 & 6722.3 \\
\hline 4 & SIM1 $10 \mathrm{~nm}$ & & 7717.2 & 7467.5 & 6677.2 & 6769.0 & 4927.1 \\
\hline 5 & SIM3 $5 \mathrm{~nm}$ & & 8385.0 & 7942.0 & 7694.5 & 7598.8 & 5826.1 \\
\hline \multicolumn{8}{|c|}{ BM1 Adhesion target: $9269.1 \pm 200 \mathrm{gf} /$ in } \\
\hline 1 & FLM 5 nm & \multirow{5}{*}{$\begin{array}{c}10,299.0 \\
\text { (gf) }\end{array}$} & $10,301.0$ & $10,347.0$ & $10,394.0$ & 9854.6 & 8430.5 \\
\hline 2 & FLM $10 \mathrm{~nm}$ & & $10,032.0$ & $10,139.0$ & 9667.7 & 9415.3 & - \\
\hline 3 & SIM1 $5 \mathrm{~nm}$ & & $10,245.0$ & 9971.9 & $10,237.7$ & $10,133.0$ & $9,300.9$ \\
\hline 4 & SIM1 $10 \mathrm{~nm}$ & & 9593.0 & 9620.0 & 9433.0 & 8878.7 & 6597.4 \\
\hline 5 & SIM3 5 nm & & $10,169.0$ & 9798.55 & 9598.2 & 8917.6 & 8263.5 \\
\hline \multicolumn{8}{|c|}{ BM2 Adhesion target: $9039.6 \pm 200$ gf/in } \\
\hline 1 & FLM 5 nm & \multirow{5}{*}{$\begin{array}{c}10,044.0 \\
\text { (gf) }\end{array}$} & $10,242.0$ & $10,554.0$ & $10,401.0$ & $10,080.0$ & 8281.5 \\
\hline 2 & FLM 10 nm & & $10,247.0$ & $10,242.2$ & $10,185.0$ & 9870.7 & 1631.1 \\
\hline 3 & SIM1 5 nm & & 9790.1 & $10,232.0$ & $10,332.0$ & $10,054.0$ & 9995.0 \\
\hline 4 & SIM1 $10 \mathrm{~nm}$ & & $10,004.5$ & $10,099.0$ & $10,006.0$ & $10,001.0$ & 8374.5 \\
\hline 5 & SIM3 5 nm & & $10,074.0$ & $10,184.0$ & $10,056.0$ & 9822.5 & 8556.7 \\
\hline
\end{tabular}

OCA was deposited by thickness with SIS and FLS using spray coating. The SIM showed difficulty in accurate thickness control, so deposition was performed using the FLM. As shown in Figure 4a, it was confirmed that the FLS thickness did not affect the 
change in light transmittance and haze. The results of adhesion by FLS deposition thickness to OCA are shown in Figure 4b. For FLS (7.8 and $10.2 \mathrm{~nm}$ ) on the WG substrate, FLS (7.8 $\mathrm{nm})$ on the BM1 substrate, and FLS $(7.8 \mathrm{~nm})$ on the BM2 substrate, an adhesion strength of $90 \%$ or more was maintained based on the initial adhesion.
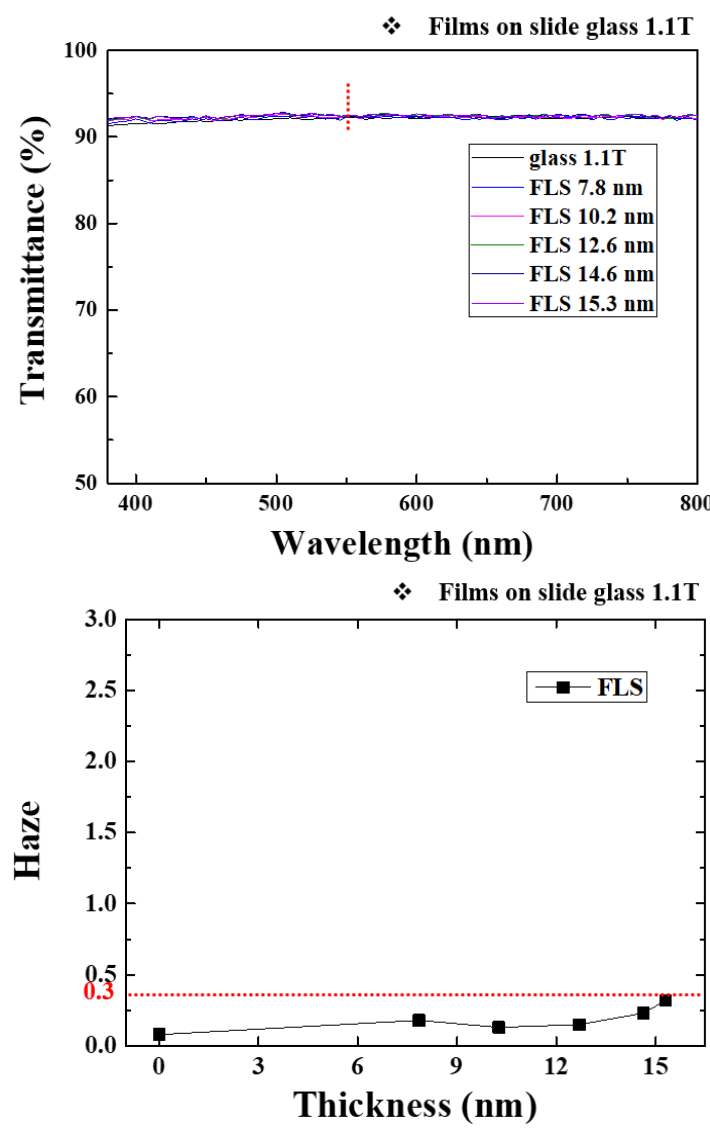

(a)

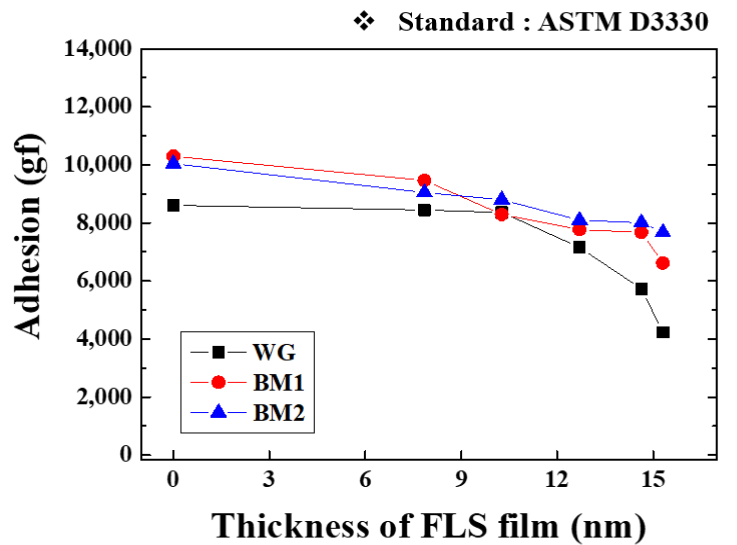

(b)

Figure 4. Adhesion change through surface-energy control on OCA; (a) Light transmittance and haze by FLS deposition thickness on OCA; (b) Adhesion according to the ratio of coated area on OCA.

\subsection{Optimal Rework Characteristics through Surface-Energy Control}

Through the above experiments, the rework characteristics (residue $0 \%$ ) of each substrate (WG, BM1, BM2) and OCA were confirmed under conditions with optimized surface-energy characteristics. The results of the visual evaluation and optical microscopy following a $180^{\circ}$ peel test are shown in Figure 5a-d. Figure $5 \mathrm{a}$ is an image of adhesion maintenance and optimal rework characteristics in WG; Figure 5b,c refer to BM1 and BM2, 
and Figure $5 \mathrm{~d}$ refers to OCA. Tables 3 and 4 summarizes the above results. In brief, there were no bumps present in the WG substrate, and residue was not left easily during the rework due to the WG substrate's low surface roughness. On the other hand, the BM1 and BM2 substrates had relatively large amounts of residue during the rework. This was due to bumps, which increase the contact area, as well as the molecule-molecule interactions caused by the bumps, as shown in Figure 2f. It can be seen that BM2 has less residue than BM1 despite BM2 having greater surface roughness. For that reason, the number of bumps on the BM2 substrate is low, the contact area during the rework is small, and the molecule-molecule interactions of the bumps are weak.

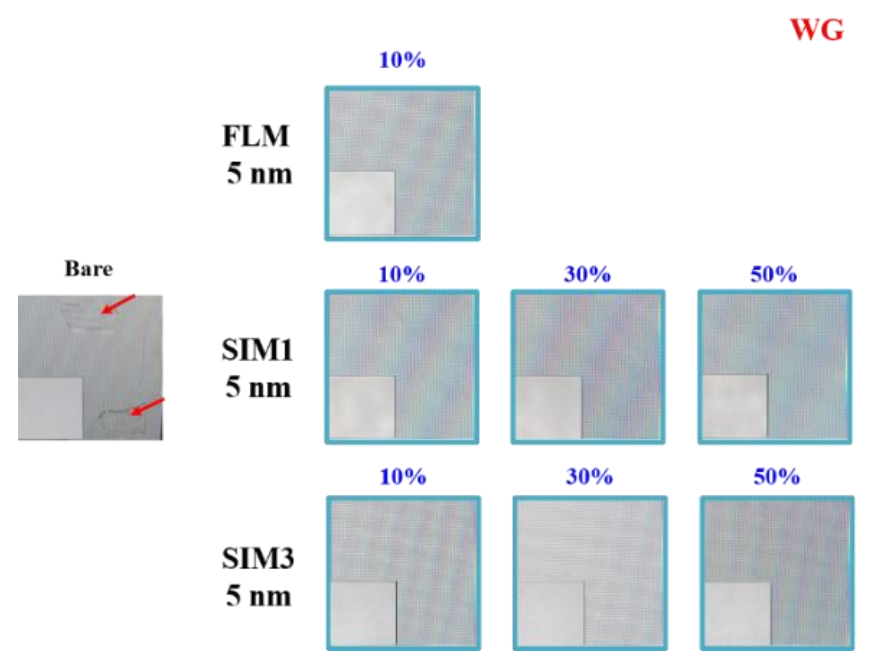

(a)

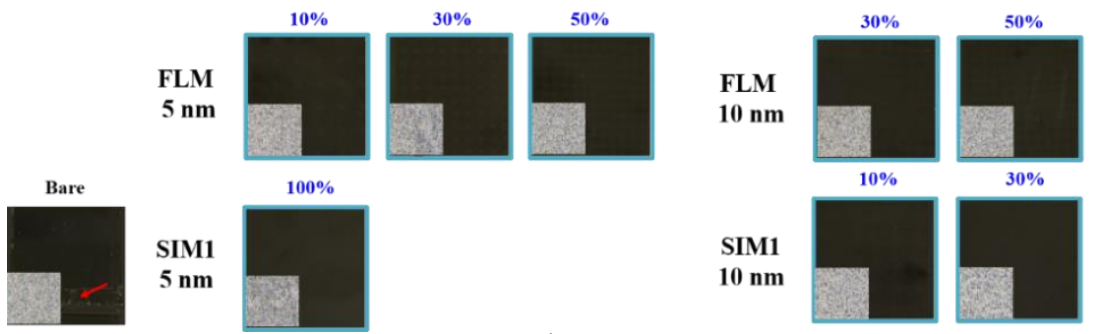

(b)

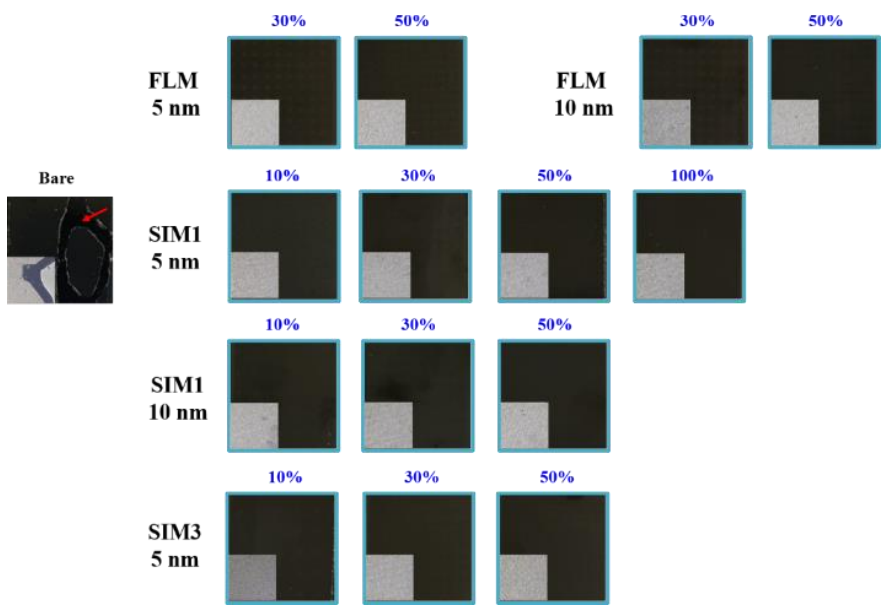

(c)

Figure 5. Cont. 


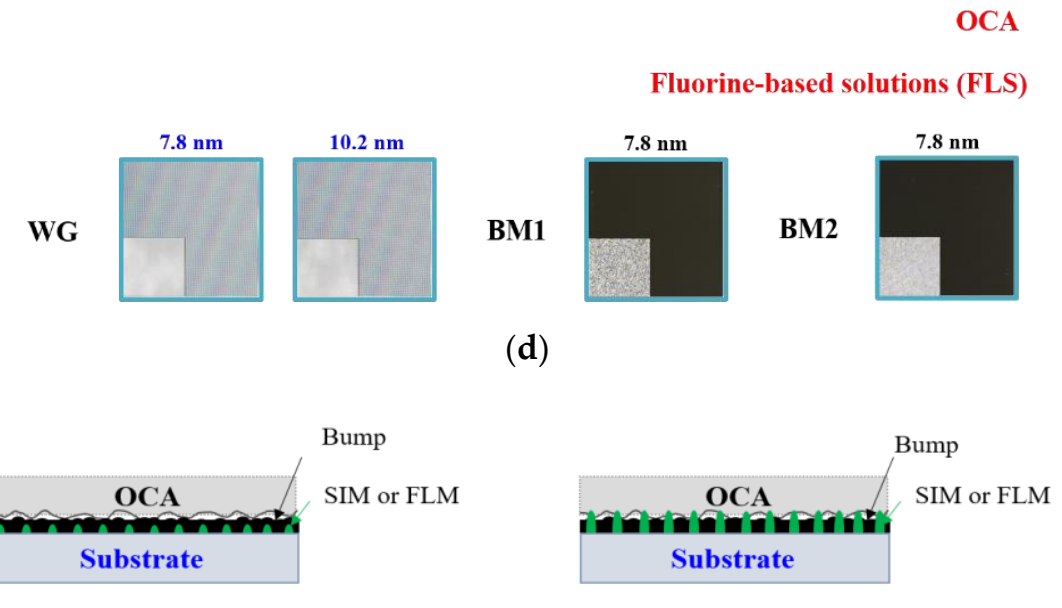

(e)

Figure 5. Optimal rework characteristics through surface-energy control; (a) Optical image: Rework characteristics according to the ratio of each material of coated area in WG; (b) Optical image: Rework characteristics according to the ratio of each material of coated area in BM1; (c) Optical image: Rework characteristics according to the ratio of each material of coated area in BM2; (d) Rework characteristics according to each substrate of OCA on which FLS is deposited; (e) The mechanism for the change in adhesion according to the SIM- or FLM-thickness difference.

Table 3. Evaluation of rework suitability according to material deposition area and type on substrates.

\begin{tabular}{|c|c|c|c|c|c|c|c|}
\hline \multirow{3}{*}{ NO. } & \multicolumn{6}{|c|}{$\begin{array}{l}\text { : Adhesion corresponding to target value Residue } 0 \% \text { : O } \\
\text { X: Adhesion corresponding not to target value NG: No good }\end{array}$} & \multirow[b]{3}{*}{100} \\
\hline & \multirow{2}{*}{ Samples } & \multicolumn{5}{|c|}{ Ratio of Coated Area (\%) } & \\
\hline & & $\mathbf{0}$ & 4 & 10 & 30 & 50 & \\
\hline \multicolumn{8}{|c|}{ WG Adhesion target: $7747.3 \pm 200 \mathrm{gf} /$ in } \\
\hline 1 & FLM $5 \mathrm{~nm}$ & \multirow{5}{*}{$X$} & NG & $\mathrm{O}$ & $X$ & $\mathrm{X}$ & $X$ \\
\hline 2 & FLM $10 \mathrm{~nm}$ & & NG & NG & $x$ & $x$ & $x$ \\
\hline 3 & SIM1 $5 \mathrm{~nm}$ & & NG & $\mathrm{O}$ & $\mathrm{O}$ & $\mathrm{O}$ & $X$ \\
\hline 4 & SIM1 $10 \mathrm{~nm}$ & & NG & $\mathrm{X}$ & $X$ & $X$ & $x$ \\
\hline 5 & SIM3 $5 \mathrm{~nm}$ & & NG & $\mathrm{O}$ & $\mathrm{O}$ & $\mathrm{O}$ & $X$ \\
\hline \multicolumn{8}{|c|}{ BM1 Adhesion target: $9269.1 \pm 200 \mathrm{gf} /$ in } \\
\hline 1 & FLM 5 nm & \multirow{5}{*}{$x$} & NG & $\mathrm{O}$ & $\mathrm{O}$ & $\mathrm{O}$ & $\mathrm{X}$ \\
\hline 2 & FLM $10 \mathrm{~nm}$ & & NG & NG & $\mathrm{O}$ & $\mathrm{O}$ & $x$ \\
\hline 3 & SIM1 $5 \mathrm{~nm}$ & & NG & NG & NG & NG & $\mathrm{O}$ \\
\hline 4 & SIM1 $10 \mathrm{~nm}$ & & NG & $\mathrm{O}$ & $\mathrm{O}$ & $\mathrm{X}$ & $X$ \\
\hline 5 & SIM3 $5 \mathrm{~nm}$ & & NG & NG & NG & $x$ & $X$ \\
\hline \multicolumn{8}{|c|}{ BM2 Adhesion target: $9039.6 \pm 200$ gf/in } \\
\hline 1 & FLM 5 nm & \multirow{5}{*}{$x$} & NG & NG & $\mathrm{O}$ & $\mathrm{O}$ & $X$ \\
\hline 2 & FLM $10 \mathrm{~nm}$ & & NG & NG & $\mathrm{O}$ & $\mathrm{O}$ & $X$ \\
\hline 3 & SIM1 $5 \mathrm{~nm}$ & & NG & $\mathrm{O}$ & $\mathrm{O}$ & $\mathrm{O}$ & $\mathrm{O}$ \\
\hline 4 & SIM1 $10 \mathrm{~nm}$ & & NG & $\mathrm{O}$ & $\mathrm{O}$ & $\mathrm{O}$ & $X$ \\
\hline 5 & SIM3 $5 \mathrm{~nm}$ & & NG & $\mathrm{O}$ & $\mathrm{O}$ & $\mathrm{O}$ & $x$ \\
\hline
\end{tabular}

The above results confirm that defects occurred in the thin depositions and the low-ratio coating area, unlike in the thick depositions and high-ratio coating area during the rework process at room temperature. This is because as the SIM- or FLM-deposition thickness increased as shown in Figure 5e, the contact area of the SIM or FLM material with low surface energy increased, and the residues were removed relatively well. To solve this problem, the results of evaluating the characteristics through temperature control during the rework process are shown in Figure 6a. It was found that the adhesive strength fell to $\leq 10 \mathrm{gf}$ at temperatures between -40 and $-20^{\circ} \mathrm{C}$. The results of confirming the rework characteristics 
after the $180^{\circ}$ peel test at $-40{ }^{\circ} \mathrm{C}$ are shown in Figure $6 \mathrm{~b}$. The peel test confirmed that no residue resulted from the reworking performed at $-40^{\circ} \mathrm{C}$. At temperatures above $-20^{\circ} \mathrm{C}$, the residue was not completely removed. As shown in Figure $6 \mathrm{c}$, when the peel test was in progress, the OCA monomer crystallized at a temperature below $-20^{\circ} \mathrm{C}$, leaving no residue. On the other hand, during the peel test in the OCA before temperature treatment, an acrylic polymer that had not been crystallized remained attached to the film. These data are shown in Figure $6 \mathrm{~b}$. Therefore, it was found that residue from the rework process can be eliminated through surface-energy control and cooling treatment by depositing FLM and SIM materials.

Table 4. Evaluation of rework suitability for each substrate of OCA on which FLS is deposited.

\begin{tabular}{|c|c|c|c|c|c|c|}
\hline \multirow{3}{*}{ Samples } & \multicolumn{5}{|c|}{$\begin{array}{l}\text { : Adhesion corresponding to target value Residue } 0 \%: \mathrm{O} \\
\mathrm{X} \text { : Adhesion corresponding not to target value NG: No good }\end{array}$} & \multirow[b]{3}{*}{15.3} \\
\hline & \multicolumn{5}{|c|}{ Thickness of FLS (mm) } & \\
\hline & $\mathbf{0}$ & 7.8 & 10.2 & 12.6 & 14.6 & \\
\hline \multicolumn{7}{|c|}{ WG Adhesion target: $7747.3 \pm 200$ gf/in } \\
\hline WG & 8608.2 (gf) & $\mathrm{O}$ & $\mathrm{O}$ & $X$ & $X$ & $X$ \\
\hline \multicolumn{7}{|c|}{ BM1 Adhesion target: $9269.1 \pm 200 \mathrm{gf} /$ in } \\
\hline BM1 & $10,299.0$ (gf) & $\mathrm{O}$ & $X$ & $X$ & $X$ & $X$ \\
\hline \multicolumn{7}{|c|}{ BM2 Adhesion target: $9039.6 \pm 200 \mathrm{gf} /$ in } \\
\hline BM2 & $10,044.0(\mathrm{gf})$ & $\mathrm{O}$ & $X$ & $x$ & $X$ & $X$ \\
\hline
\end{tabular}




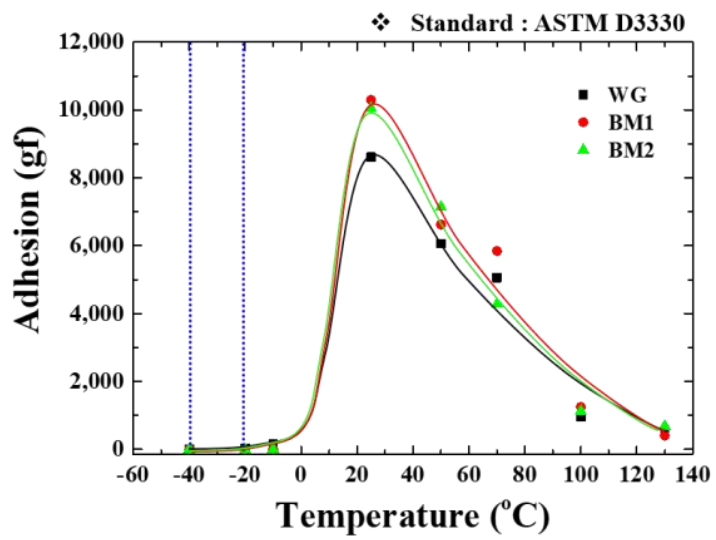

(a)
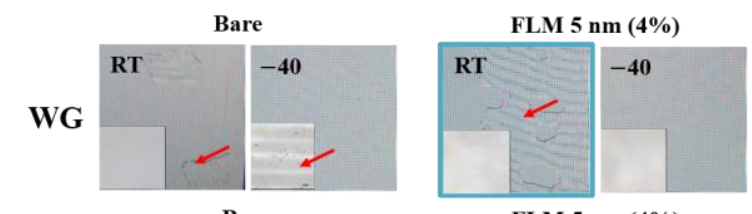

FLM 5 nm (4\%)

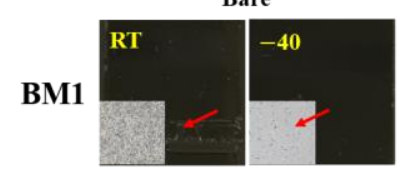

Bare

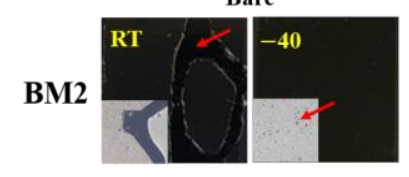

Before treatment

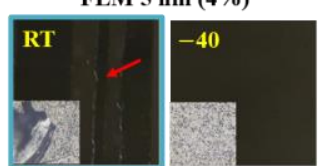

FLM 5 nm (4\%)

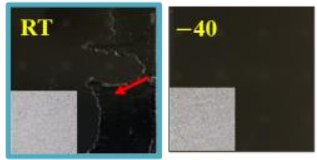

After FLM treatment

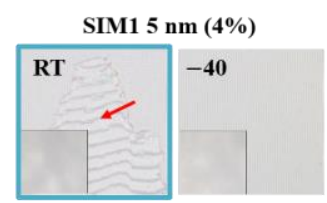

SIM1 5 nm (4\%)

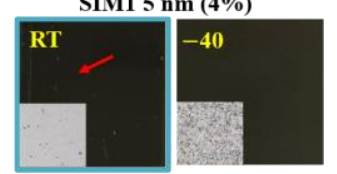

SIM1 $5 \mathrm{~nm}(4 \%)$

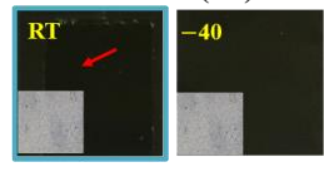

After SIM1 treatment

(b)

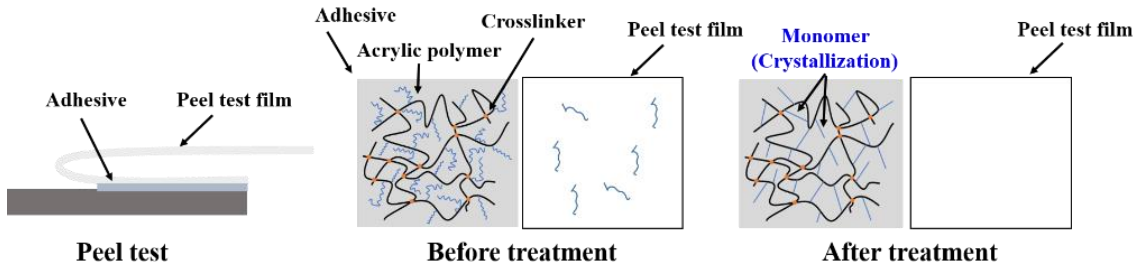

(c)

Figure 6. Improvement of rework characteristics through temperature treatment; (a) Confirmation of changes in adhesion according to temperature; (b) Differences in rework characteristics before and after temperature treatment; (c) Schematic diagram of the mechanism of residue difference upon peeling after temperature treatment.

\section{Conclusions}

In this paper, we presented a study on substrate-surface treatments. This study was conducted in order to recycle defective substrates that are generated during the lamination process, which are bonding panel substrates and bended window glass. In order to secure high-adhesive properties and high-efficiency rework properties of $0 \%$ residue, an experiment was conducted in order to lower the surface energy, which in turn lowered the adhesion of the coating materials. FLM- and SIM-containing organic materials that can lower the surface energy were deposited onto the substrate surfaces and the OCA. In addition, the coating area was controlled in order to control the surface energy, which resolved the problem of abruptly lowering the adhesive strength between the coating and the substrate. In this way, an experiment was conducted to remove the OCA at room temperature in order to confirm the rework characteristics of the substrate with low surface 
energy through surface-energy control. The surface inspection (via visual inspection and using an optical camera) of the samples with the OCA removed confirmed that the residue was in fact removed as the surface energy decreased at room temperature. However, it was difficult to completely remove the residue at room temperature. This challenge was resolved by an additional cooling treatment that was performed on the surface-coated substrate in which the residue was completely removed by crystallizing the OCA monomer. Therefore, surface-energy control and cooling treatments for various substrates could make the defective substrates that are generated during the lamination process reusable. These results could contribute to the improvement of the lamination process technology and productivity of the next-generation displays that are under development and continually evolving.

Author Contributions: Data curation, Y.-G.K., B.-M.P., J.-K.C. and D.-H.J.; formal analysis, Y.-G.K., B.-M.P., J.-K.C. and D.-H.J.; project administration, Y.-G.K. and K.-Y.H.; supervision, K.-Y.H.; writingoriginal draft, Y.-G.K. and B.-M.P.; writing—review and editing, B.-M.P. and K.-Y.H. All authors have read and agreed to the published version of the manuscript.

Funding: This research received no external funding.

Institutional Review Board Statement: Not applicable.

Informed Consent Statement: Not applicable.

Data Availability Statement: Data sharing is not applicable to this article.

Conflicts of Interest: The authors declare no conflict of interest.

\section{References}

1. Grego, S.; Lewis, J.; Vick, E.; Temple, D. Development and evaluation of bend-testing techniques for flexible-display applications. J. Soc. Inf. Disp. 2005, 13, 575-581. [CrossRef]

2. Park, J.H.; Heo, S.H.; Park, K.B.; Song, M.H.; Kim, J.Y.; Kyung, G.H.; Rodney, S.R.; Park, U.J.; Franklin, B. Research on flexible display at Ulsan National Institute of Science and Technology. NPJ Flexible Electron. 2017, 1, 9. [CrossRef]

3. Tan, G.; Lee, J.-H.; Lan, Y.-H.; Wei, M.-K.; Peng, L.-H.; Cheng, I.-C.; Wu, S.-T. Broadband antireflection film with moth-eye-like structure for flexible display applications. Optica 2017, 4, 678-683. [CrossRef]

4. Axel, S.; Jochen, B.; Norbert, F.; James, P.N.; Zvi, Y. Solution-deposited carbon nanotube layers for flexible display applications. Physica E Low-Dimens. Syst. Nanostruct. 2007, 37, 119-123.

5. Chen, X.; Liu, B.; Zhong, C.; Liu, Z.; Liu, J.; Ma, L.; Deng, Y.; Han, X.; Wu, T.; Hu, W.; et al. Ultrathin $\mathrm{Co}_{3} \mathrm{O}_{4}$ layers with large contact area on carbon fibers as high-performance electrode for flexible zinc-air battery integrated with flexible display. Adv. Energy Mater. 2017, 7, 1700779. [CrossRef]

6. Shim, H.; Kee, I.; Kim, S.; Chun, Y.; Kwon, H.-J.; Jin, Y.; Lee, S.; Han, D.; Kwack, J.; Kang, D.; et al. 18.4: A new seamless foldable OLED display composed of multi display panels. SID Symp. Dig. Tech. Pap. 2010, 41, 257-260. [CrossRef]

7. Ryu, K.; Ryo, N.; Takeru, S.; Akio, S.; Naoyuki, S.; Takuya, K.; Hisao, I.; Shingo, E.; Yoshiharu, H.; Shunpel, Y.; et al. Repeatedly foldable book-type AMOLED display. SID Symp. Dig. Tech. Pap. 2014, 45, 326-329.

8. Khalilbeigi, M.; Lissermann, R.; Kleine, W.; Steimle, J. Interacting with Double-Sided Foldable Displays. In Proceedings of the Sixth International Conference on Tangible, Embedded, and Embodied Interaction, Kingston, ON, Canada, 19-22 February 2012; Association for Computing Machinery: New York, NY, USA, 2012; pp. 33-40.

9. Gomes, A.; Vertegaal, R. Evaluating Shape Changes for Viewport Transformations in Foldable Thin-Film Display Devices. In Proceedings of the Sixth International Conference on Tangible, Embedded, and Embodied Interaction, Stanford, CA, USA, 15-19 January 2015; Association for Computing Machinery: New York, NY, USA, 2015; pp. 153-160.

10. Ryu, K.; Ryo, N.; Takeru, S.; Akio, S.; Naoyuki, S.; Takuya, K.; Yasuhiro, J.; Tomoya, A.; Naoto, O.; Susumu, K., I; et al. Repeatedly foldable AMOLED display. J. Soc. Inf. Disp. 2015, 23, 41-49.

11. Fay, S.; Albert, E.; Chris, C.; Brian, P.; Belma, E.H.; Gregg, C. Modeling the mechanical performance of a foldable display panel bonded by 3M optically clear adhesives. SID Symp. Dig. Tech. Pap. 2017, 48, 938-941.

12. Raghuwanshi, V.; Bharti, D.; Tiwari, S.P. Flexible organic field-effect transistors with TIPS-Pentacene crystals exhibiting high electrical stability upon bending. Org. Electron. 2016, 31, 177-182. [CrossRef]

13. Mohanta, K.; López-Quintela, M.A.; Rivas, J. Conductive nonwetting flexible substrate. Org. Electron. 2017, 46, 247-252. [CrossRef]

14. Ahn, S.H.; Jin, B.; Kwon, S.; Yun, M.H. A research on curved display comparing to flat display regarding posture, tilt angle, focusing area and satisfaction. J. Ergon. Soc. Korea 2014, 33, 191-202. [CrossRef]

15. Wang, W.; Chen, G.; Weng, Y.; Weng, X.; Zhou, X.; Wu, C.; Guo, T.; Yan, Q.; Lin, Z.; Zhang, Y. Large-scale microlens arrays on flexible substrate with improved numerical aperture for curved integral imaging 3D display. Sci. Rep. 2020, 10, 11741. [CrossRef] [PubMed] 
16. Makoto, N.; Norihito, K.; Mao, K.; Akira, Y.; Shinichi, U.; Ryouichi, Y.; Nobukazu, H.; Gen, Y.; Iwao, Y.; Kazumasa, N.; et al. An OTFT-driven rollable OLED display. J. Soc. Inf. Disp. 2011, 19, 316-322.

17. Makoto, N.; Norihito, K.; Mao, K.; Akira, Y.; Shinichi, U.; Ryouichi, Y.; Nobukazu, H.; Gen, Y.; Iwao, Y.; Kazumasa, N.; et al. A rollable AM-OLED display driven by OTFTs. SID Symp. Dig. Tech. Pap. 2010, 41, 710-713.

18. Kazumasa, N.; Makoto, N.; Norihito, K.; Mao, K.; Akira, Y.; Shinichi, U.; Ryoichi, Y.; Nobukazu, H.; Gen, Y.; Iwao, Y. Invited paper: Rollable OLED display driven by organic TFTs. SID Symp. Dig. Tech. Pap. 2011, 42, 488-491.

19. Khalilbeigi, M.; Lissermann, R.; Mühlhäuser, M.; Steimle, J. Interaction Techniques for Rollable Displays. In Proceedings of the SIGCHI Conference on Human Factors in Computing Systems, Vancouver, BC, Canada, 7-12 May 2011; Association for Computing Machinery: New York, NY, USA, 2011.

20. Huitema, E.; Touwslager, F.; Veenendaal, E.V.; Aerie, N.V.; Lieshout, P.V. Invited paper: Rollable displays: From concept to manufacturing. SID Symp. Dig. Tech. Pap. 2009, 40, 104-107. [CrossRef]

21. Kim, Y.-G.; Park, B.-M.; Han, K.-Y. A study on the spreading characteristics of OCR lamination for flexible OLED. Jpn. J. Appl. Phys. 2020, 59, 080901. [CrossRef]

22. Kim, Y.-G.; Han, K.-Y. Spread characteristics of OCR lamination for flexible OLED display process with flat and curved substrates. Jpn. J. Appl. Phys. 2021, 60, 056504. [CrossRef]

23. Kim, Y.-G.; Park, B.-M.; Han, K.-Y. P-134: A study on spreading characteristics of resin. SID Symp. Dig. Tech. Pap. 2019, 50, 1617-1619. [CrossRef]

24. Lee, B.-C.; Park, B.-M.; Han, K.-Y. Optimal slit nozzle design for uniformity coating in display module lamination. Mol. Cryst. Liq. Cryst. 2018, 677, 42-53. [CrossRef]

25. Hu, G.; Jin, L.; Jin, Z.; Wang, X.; You, M.; Xu, C.; Jiang, Z. P-63: Improving peeling force for cover glass lamination to display panels. SID Symp. Dig. Tech. Pap. 2018, 49, 1436-1439. [CrossRef]

26. Kim, H.S.; Hwang, H.D.; Han, K.Y. Ink-Step Adaptability and reliability of maleimide-functionalized UV-curable optically clear adhesives. Nanosci. Nanotechnol. Lett. 2017, 9, 1146-1152. [CrossRef]

27. Huang, P.S.; Chang, M.C.; Chen, Y.C. Minimizing the impact of plastic-cover-lens bonding-induced delay bubble. SID Symp. Dig. Tech. Pap. 2016, 47, 1838-1840. [CrossRef]

28. Kim, J.S.; Jang, K.S.; Phu, C.; Park, H.J.; Shin, D.G.; Lee, Y.J.; Yi, J.S. Enhancement of transmittance and adhesion of flexible display adhesion surface by bubble removing process. J. Korean Inst. Electr. Electron. Mater. Eng. 2018, 31, 330-334.

29. Jang, D.-H.; Han, K.-Y. Multi-hardness hybrid silicone pad to laminate the bended cover window in a flexible OLED display. J. Mech. Sci. Technol. 2021, 35, 1987-1992. [CrossRef]

30. Lim, S.-W.; Jang, D.-H.; Park, B.-M.; Han, K.-Y. Optimized design of silicone pad for bended window lamination in organic light-emitting diodes. J. Mech. Sci. Technol. 2019, 33, 5829-5835. [CrossRef]

31. Yeh, W.; Seigo, M. Crystallinity Study of Si Single Crystal Stripe on Bended Glass Substrate Fabricated by Micro-Chevron Laser Beam Scanning Method. In Proceedings of the 2017 IEEE Electron Devices Technology and Manufacturing Conference, Toyama, Japan, 28 February-2 March 2017; pp. 257-258.

32. Anton, D. Surface-Fluorinated Coatings. Adv. Mater. 1998, 10, 1197-1205. [CrossRef]

33. Brassard, J.-D.; Sarkar, D.; Perron, J. Fluorine based superhydrophobic coatings. Appl. Sci. 2012, 2, 453-464. [CrossRef]

34. Wu, W.; Wang, X.; Liu, X.; Zhou, F. Spray-coated fluorine-free superhydrophobic coatings with easy repairability and applicability. ACS Appl. Mater. Interfaces 2009, 1, 1656-1661. [CrossRef]

35. Fabbri, P.; Messori, M.; Montecchi, M.; Pilati, F.; Taurino, R.; Tonelli, C.; Toselli, M. Surface properties of fluorinated hybrid coatings. J. Appl. Polym. Sci. 2006, 102, 1483-1488. [CrossRef]

36. Waddell, T.G.; Leyden, D.E.; DeBello, M.T. The nature of organosilane to silica-surface bonding. J. Am. Chem. Soc. 1981, 103, 5303-5307. [CrossRef]

37. Surivet, F.; My, L.T.; Pascault, J.P.; Tho, P.Q. Organic-inorganic hybrid materials. 1. Hydrolysis and condensation mechanisms involved in alkoxysilane-terminated macromonomers. Macromolecules 1992, 25, 4309-4320. [CrossRef]

38. Hall, J.R.; Westerdahl, A.C.; Devine, A.T.; Bodnar, J.M. Activated gas plasma surface treatment of polymers for adhesive bonding. J. Appl. Polym. Sci. 1969, 13, 2085-2096. [CrossRef]

39. Kaplan, S.; Rose, P. Plasma surface treatment of plastics to enhance adhesion. Int. J. Adhes. Adhes. 1991, 11, 109-113. [CrossRef]

40. Leahy, W.; Barron, V.; Buggy, M.; Young, T.; Mas, A.; Schue, F.; McCabe, T.; Bridge, M. Plasma surface treatment of plastics to enhance adhesion. J. Adhes. 2001, 77, 215-249. [CrossRef] 